independencia y acercándose a un sentido humano amplísimo, su camino ya no se detendrá sino hasta llegar a límites insospechados y sorprendentes.-M A N U L R O J A S.

\title{
Glosa del individualismo español
}

TIENTRAS avanzaba el enemigo devastando ciudades, la energía indomable de Clemenceau era la voz de aliento para la Francia invadida. Todos los espíritus se hallaban fatigados y perdidas todas las esperanzas cuando la suerte de la guerra se puso en manos del estadista genial. Al ser convertido éste en director, en Patriarca de los pueblos aliados, llegó al Parlamento para decir con su natural y terrible crudeza: $A$ mi edad no he venido al Gooierno para perder el tiempo; he venido para hacer la guerra. Y este fué su estribillo durante largo tiempo. En su voz se cernía un eco de La Marsellesa. Los poilus lo apodaron El Tigre al verlo en los campos de batalla, entre los generales, en medio de la muerte, tranquilo, sólido, firme. Hacía la guerra, hacía la victoria y, más tarde, hizo la paz en la asamblea de las naciones vencedoras.

Pasados los trágicos momentos de peligro, quiso la República investir de la Suprema Magistratura al Padre la Vicioric; pero fracasó su candidatura presidencial y volvió al retiro de su estudio, a continuar sus obras, sin que sus energías desmayaran un solo instante, sin sentir siquiera el desfallecimiento de la ancianidad.

Ninguna otra circunstancia de la política francesa, en los últimos años, contiene una enseñanza más trascendental que esta. La disciplina colectiva, la existencia de sólidos principios determinan la supervivencia de la vida nacional, de las actividades políticas, tras el desaparecimiento de su figura máxima. En tal ambiente, cada cual es el hombre de una hora, de una necesidad, de un deber, sin requerir universalidad de conocimientos ni multiplicidad de actuaciones. Asíse alcanza una cultura cívica suficiente para hacer comprender al estadista cuándo ha pasado su hora e impulsarlo a continuar sus trabajos particulares, sin pretender enseñorearse del poder, mientras presta conformidad a las masas y las enseña a no 
persistir en idealismos perjudiciales que no acarrean más que desorientaciones.

En España, por desgracia, no sucede lo mismo; a ello se deben, en gran parte, los reveses de fortuna y las inquietudes del momento actual, No sin razón dicen filósofos y publicistas que la crisis de este país no es de sistemas sino de hombres. Para comprender la trascendencia de esta desgracia, es necesario medir la influencia perniciosa y preponderante del $\mathrm{Ca}$ ciquismo.

Derivado de una torpe educación o de matices psicológicos, el individualismo existe en España. Allí se crean eminencias por simpatías personales y las cosas se hacen a lo amigo. Cuando falta un hombre de temperamento y de las condiciones que son necesarias para reunir la amistad de la mayoría, la vida política se sale de madre, todo se desborda, se transtorna, mientras cada cual preconiza aisladamente sus particulares puntos de vista.

El maravilloso libro de Luis Araquistain El ocaso de un régimen, aparecido recientemente (1), nos dice que el español no ve los círculos concéntricos que forman la vida del hombre: familia, sociedad nacional, sociedad universal, humanidad; si no que se encierra dentro del círculo más pequeño y reduce su vida al medio familiar. De este modo se acrecienta el utilitarismo - por cuanto cada uno señala una meta a sus aspiraciones en el bienestar que ha de proporcionar a los suyos el favoritismo-en virtud de las reducciones que sufre la visión de cada individuo-; la incompetencia, la venalidad y la deslealtad - como corolarios lógicos del favoritismo, así como el menosprecio por el trabajo y el espíritu de empresa-; y el fatal predominio del espíritu privado sobre el espíritu público.

De esta suerte, desaparecidas de la escena política las figuras que en otro tiempo fueron predominantes, el pueblo no sabe qué hacer, ni a dónde dirigirse, mientras los pequeños y aislados núcleos sobrevivientes pierden cohesión en la inútil disputa personalista.

A este individualismo, de suyo funesto, se suman los males de una característica que le es propia. La que Jean Cassou (2) denomina el adanismo. El que logra surgir y destacarse es una especie de Adán, en medio del Paraíso desierto. Ha de crearlo todo, formar ambiente, organizar, edificar artificiosa-

(1) Luis Araquistain, El ocaso de un régimen. Edit. España. Madrid, 1930. (2) Jean Cassou, Littérature espagnole. Edit. Kra. París, 1929. 
mente una realidad; lo cual le obliga a la universalidad de conocimientos, esto es, a nociones generales acerca de todo, que le permitan servir hoy en una cartera y mañana en otra, afrontar todo género de dificultades y buscar soluciones a los problemas más heterogéneos.

El político que ha logrado relieve, que escala el poder $y$ consigue formar ese ambiente, crear esa vida artificial y despertar esas aspiraciones, cree que ha fundado a España; no se aviene fácilmente con renunciar y retirarse a la vida privada; se siente acreedor de sus conciudadanos y no sabe conformarse. En la crisis ve una manifestación de ingratitud. Se rebela contra ella; y como debió su predominio a atracciones personales, a simpatía, ha llegado, con mayor facilidad que otros, al máximum del envanecimiento. Por otra parte, sus electores no saben renunciar a este género de debilidades sentimentales, no abdican su apasionamiento, sino que urgen a su favorito, lo inducen a la rebeldía, le hacen creer que es merecedor ai eterno poder, puesto que le asiste la sabiduría infalible, hasta que logran decidirlo y luchan por imponerlo. Por eso las crisis no se reducen a cambios de gobierno, más o menos difíciles de realizar, sino que se traducen en inquietudes, en disturbios populares, en angustias; porque las crisis equivalen a renuncia del Gobierno y... pronunciamiento.

Como vive encerrado en el círculo doméstico, usa de éste como fin y no como medio, sin concebir ideas universales. Y es feliz el español con su presuntuosa ignorancia, con su desdén por el trabajo y el espíritu de empresa. Ha situado el máximum de la perversidad en la ambición; y ambiciosos llama a todos aquellos que conciben algo con la esperanza de trascender y trasponer las fronteras. Ha olvidado que hay algo, una partícula, de humanidad en su persona. Y se dedica a buscarse la vida, a hacer carrera, procurándose bienestar e influencias por medio de gestiones familiares. No se muestra arbitrario Araquistain al decirnos que raro es el español que no lleva dentro ien mendigo, un pedigüeño crónico.

$Y$, sin embargo, fué en otras épocas individuo de conceptos universales. No tuvieron, entonces, límite sus aspiraciones. En su imperio no se ponía el sol. Descubridor, colonizador, catequizador, se consideraba ciudadano del mundo. Aspiraba a destacarse, a predominar y a redimir. Su último gesto de universalidad está condensado en las guerras de la Independencia. Pero en ellas también se engendra en cierto modo el funesto individualismo de hoy día. La fabulosa importancia que en ellas alcanzó el guerrillero demuestra el descubrimiento que hacían

Atenea. -14 
los españoles de su propio valor, abandonados a su inspiración personal, desechada la tutela de un Estado podrido. El pueblo logró acertar fundándose en su propia virtud. Los piojosos vencieron a las brillantes tropas del Imperio. Pero este rescate de la voluntad personal fué gastándose y concluyó por degenerar. Aquellas guerras hicieron posible el bandolerismo que ensangrentó la tierra española durante el reinado de Fernando y de su hija. Y en esta forma ulterior, la energía resucitada perdió utilidad social. Al decir de Manuel Azaña (1):

Ramón Cabrera nació tarde: hubiera afilado su garra contra los franceses, $y$ hoy tendria estatuas, sin dejar de ser el mismo hombre. Muchos nacieron tardiamente, cada vez más anacrónicos, fuera de la ley del Estado, que ya no podía alistarles para fines gloriosos.

Luego viene el romanticismo a exaltar esta condición del individualismo. El pueblo, según él, ha vivido una epopeya; se le observa, se le admira, se le imita. En su presencia se cree estar en la presencia de la verdadera, de la única España. Gautier se viste de majo en Granada; la Condesa de Tebas luce marsellés con alamares; el Duque de Alba, el Marqués de Alcañices y otros nobles se visten de corto en Toledo, pasean por sus calles, visitan la Catedral. El Duque de Montpensier, casado con la hermana de la Reina, gasta 25 mil reales en vestirse a la usanza sevillana. El tipo burgués, ascendente en la vida social, no tiene prestigio, suscita la vena cómica. Y el extranjero, deseoso de españolismo recio, no acierta a descubrirlo más que en el pueblo.

Así los tipos populares se destacan y como no tienen enjundia propia, como nada hay en ellos que resista el detenido análisis de quien no quiera conformarse sólo con lo pintoresco, pierden su posición. Tcdo ese pasado glorioso, esas energías indomables, ese anhelo de grandezas, de poderío y de rumbo, se refugia en el redondel de la plaza de toros, donde el torero, único héroe fopular sobreviviente, da testimonio de la gallardía española.

España, que no vaciló en aceptar las responsabilidades de potencia dominante, que no se sintió arredrada ante los peligros de la conquista, de la colonización y de la catequización; España que no se detuvo ante la cruz que espera a todos los redentores y que dió vida al Quijote, ante la trágica visión de la gran guerra se llenó de pavor. Huyó del conflicto forque sus ideas habían perdido universalidad. Se escudó tras de la

(1) Manuel Azaña, Juán Valera en Italia. Edit. Páez. Madrid, 1929. 
pena que tendrían las madré españolas si la nación hubiera enviado hombres a las trincheras. Buscó justificación en razones domésticas. Vió los inconvenientes que iban a sufrir las familias; las inquietudes y los sinsabores que amargarían a las amistades. Y si mantiene la guerra en Marruecos, no es para conservar el espiritu católico y colonizador de los antepasados, sino -como lo expresan claramente muchos autores-para servir a los amigos con suculentos contratos de aprovisionamientc.

Así, sin ideas universales, sin orientaciones definidas, viviendo en la intimidad mezquina del hogar, dependiendo de prejuicios e intereses creados, la vida política española, en circunstancias difíciles, como las de hoy día, no es más que desorientación y perplejidad. Faltan hombres. $Y$ no existe conciencia colectiva.-F. OR T Ú Z A R V I A L .

\section{Crónica de espectáculos}

FUNESTAS CONSECUENCIAS DEL CINE SONORO.- - «A MAGIA ROJA", "LA FAVORITA DEL ZAREVICH» Y \&LA MARAVILLOSA MENTIRA DE NINA PETROWNA», TRES CINTAS MEDIOCRES.- «MANOLESCU》Y LA CENSURA.

- $A$ A PRECONIZACION del nuevo medio de expresión que significa el cine mudo no equivale solamente a la defensa de principios estéticos y a la aspiración de elevar el nivel de la cultura. El arte es conductor de ideas universales, ejerce una importante función social, y entre todas sus manifestaciones ninguna representa mejor que el cinematógrafo el medio de lograr directamente este objetivo. Hasta hace poco tiempo, paralela al progreso de la técnica, existía la divulgación de ideas profundas que destacaban el aspecto serio, el matiz psicológico, el sentido de la vida. Varietés, $Y$ el mundo marcha, Amanecer, ¿Dónde está el padre de mi hijo? y tantas otras producciones de relevantes méritos, no constituyeron simple manifestación de belleza, sino que utilizaron sus elementos artísticos para llamar la atención de las muchedumbres hacia problemas trascendentales y pensamientos de cierta calidad filosófica, que denotaban una loable preocupación intelectual. Y he ahí la razón de la funesta in. fluencia ejercida por el cine sonoro. Sin detenernos a considerar el escaso valor estético que logran sus producciones, podemos apreciar el desplazamiento que realiza del ánimo de los espectadores hacia la musicalidad. Y como la industria ha de aten- 